\title{
Evaluation of Antimicrobial and Antioxidant Properties of Phytogenic Feed Additives
}

\author{
Neha Sharma* and Tribhuwan Sharma \\ Department of Animal Nutrition, College of Veterinary and Animal Science, Rajasthan \\ University of Veterinary and Animal Sciences, Bikaner, India
}

*Corresponding author

Keywords

Ajwain,

Antioxidant,

Antimicrobial,

Cinnamon

Article Info

Accepted:

15 December 2020

Available Online:

10 January 2021
The present study was designed to examine in-vitro antimicrobial and antioxidant activity of Cinnamon bark and Ajwain seed extract by using well diffusion method and DPPH scavenging activity, respectively. It was determined that both Cinnamon and Ajwain possess considerable antibacterial activity against Staphylococcus aureus, Pseudomonas aeruginosa, Proteus vulgaris, Salmonella typhi and Escherichia coli. In terms of DPPH activity, Cinnamon showed higher antioxidant power as compared to Ajwain. These findings suggested the potential use of Cinnamon and Ajwain as phytogenic growth promoter in feed industry which can be further explored for better production.

\section{Introduction}

Herbs and plant extracts or natural feed additives used in animal feed, also referred as phytogenics feed additives, are defined as compounds of plant origin incorporated into animal feed in order to enhance performance and productivity by improving digestibility, nutrient absorption and elimination of undesirable gut pathogens (Athanasiadou et al., 2007). Phytogenic feed additives have antimicrobial, antiviral, anti-parasitic, antifungal, antioxidant and anti-helminthic properties due to the presence of phytochemical or bioactive chemicals in plants (Fulton et al., 2002). Due to drug resistance and residual effect issue associated with antibiotics, these natural plant extracts have been screened for their potential uses as alternative medicines for the treatment of many infections and improving animal performance along with safe meat production for human consumption.

Cinnamon also known as "dalchini", is a spice obtained from the inner bark of many tree species from the genus Cinnamomum, family Lauraceae, being widely used as condiment in India with many medicinal properties. Various parts of the cinnamon are 
used in Ayurvedic and ethnomedicine. The active principle comprises of principal component or essential oil, cinnamaldehyde, as well as numerous other constituents, including eugenol. Another one is Ajwain or Trachyspermum ammi, also known as ajowan caraway, or carom is an annual herb in the family Apiaceae. It is one of the ancient medicinal, aromatic and a spice plant which has been used to cure several stomach disorders along with respiratory distress. Medicinal properties of the plant include antioxidant, antispasmodic, antimicrobial and antifungal (Zareshenas, 2013). Khajeh et al., (2004) reported the active ingredients of the ajwain plant include six major chemical compounds including $49 \%$ thymol, $30.8 \% \gamma$ terpinene, $15.7 \%$ p-cymene, $2.1 \%$ b-pinene, $0.8 \%$ myrcene and $0.7 \%$ limonene. In order to explore more regarding the properties of these herbs, the aim of this present study is to estimate the antimicrobial and antioxidant properties of these natural feed additives which eventually allow the determination of its suitability as an alternative to antibiotic growth promoters in livestock and poultry production.

\section{Materials and Methods}

\section{Antibacterial activity}

The dried sample of Cinnamon bark and Ajwain seeds was ground and crude extract was prepared by Soxhlet extraction method using ethyl acetate. Five grams of powdered sample of Cinnamon and Ajwain were filled in thimble directly, was placed in Soxhlet apparatus, and extracted using ethyl acetate for $24 \mathrm{hrs}$ or until the solvent in siphon tube of the extractor become colorless. The extracts were then concentrated in pre weighted vials on a rotary evaporator below $50^{\circ} \mathrm{C}$. Dried extracts were weighed and reconstituted with a known volume of solvent and were stored in vials at $4{ }^{\circ} \mathrm{C}$ for further experimental studies. Antibacterial activities of various herbal extracts were examined by the well diffusion method (Murray et al., 1995). The test organisms used are Staphylococcus aureus, Pseudomonas aeruginosa, Proteus vulgaris, Salmonella typhi and Escherichia coli. Stock cultures were maintained at $4^{\circ} \mathrm{C}$ in nutrient broth. Active cultures for experiments were prepared by transferring a loopful of cells from the stock cultures to test tubes of nutrient broth for bacteria that were incubated without agitation for $24 \mathrm{~h}$ at $37^{\circ} \mathrm{C}$. Media was prepared by dissolving $0.5 \%$ Peptone, $0.3 \%$ beef extract/yeast extract, $1.5 \%$ agar, $0.5 \%$ $\mathrm{NaCl}$ in $100 \mathrm{ml}$ distilled water and autoclaved at $121^{\circ} \mathrm{C}$ for $15 \mathrm{~min}$. Wells were prepared on agar plates to which $100 \mu \mathrm{l}$ extract and solvent in control well was inoculated and the plates were kept for incubation at $37^{\circ} \mathrm{C}$ for 24 $h$. At the end of incubation, inhibition zones (mm) formed around the wells were measured with a transparent ruler.

\section{Radical DPPH scavenging activity}

The antioxidant activity of both extracts was measured in terms of hydrogen donating or radical scavenging ability using the stable DPPH (2,2-diphenyl-1-picryhydrazyl radical) method as modified by Sanchez-Moreno et al (1998). A methanolic solution $(0.1 \mathrm{ml})$ of the sample at various concentrations (upto $150 \mu \mathrm{g} / \mathrm{ml})$ were added to $2.9 \mathrm{ml}$ of DPPH (60 $\mu \mathrm{M})$ solution. When DPPH reacts with an antioxidant compound that can donate hydrogen, it gets reduced and the resulting decrease in absorbance at $517 \mathrm{~nm}$ was recorded at 10 min intervals up to $30 \mathrm{~min}$ using a UV-Vis spectrophotometer and the mean values were obtained from triplicate experiments. The remaining concentration of $\mathrm{DPPH}$ in the reaction medium was calculated from a calibration curve. Scavenging activity was calculated as: 
\{(Absorbance of control sample Absorbance of sample with herb extract) / Absorbance of control sample $\} * 100 \%$.

\section{Results and Discussion}

In the present investigation, in vitro antibacterial activity of crude extract of Cinnamon bark and Ajwain seeds was qualitatively assessed based on the zone of inhibition. The zone of inhibition (Table 1) for ethyl acetate extract of Cinnamon against $S$. aureus is more than that of Ajwain. Relatively larger zone of inhibition ( $\mathrm{mm}$ ) was observed for both herbal extracts against $P$. aeruginosa. Comparatively smaller zone of inhibition (mm) was obtained against S. typhi. Results of present study showed considerable antibacterial activity of Cinnamon and Ajwain against all tested organisms.

The mechanism of action of phytogenic feed additive depends on their chemical composition, and their antimicrobial activity is not attributable to a single mechanism but is instead a cascade of reactions involving the entire bacterial cell (Nazzaro et al., 2013). However, it is accepted that the antimicrobial activity depends on the lipophilic character of the components. The components permeate the cell membranes and mitochondria of the microorganisms and inhibit the membrane bound electron flow hampering energy metabolism. High concentrations may also lead to lysis of the cell membranes and denaturation of cytoplasmic proteins (Nazzaro et al., 2013). The present findings of antibacterial property of Cinnamon falls in agreement with those of Goni et al (2009) who described the antibacterial activity of cinnamon and other essential oils against Gram-positive organisms (Listeria monocytogenes, Enterococcus faecalis, Staphylococcus aureus, and Bacillus cereus), as well as against Gram-negative bacteria (Salmonella choleraesuis, Escherichia coli, Pseudomonas aeruginosa, and Yersinia enterocolitica). Likewise, Hameed et al (2016) evaluated antibacterial activity of Cinnamomum zeylanicum against Proteus mirabilis, Pseudomonas aeruginosa, Escherichia coli, Klebsiella pneumonia, Staphylococcus aureus and observed zone of inhibition as 4.92, 3.99, 5.39, 6.12 and 5.19 $\mathrm{mm}$, respectively. The current observations regarding antibacterial activity of Ajwain is also supported by results of Salma and Ramakrishnan (2018) who observed zone of inhibition against Escherichia coli, Klebsiella pneumonia, Salmonella typhi and Proteus vulgaris to be 10,11, 9 and 13, respectively. Phenol, alcohols, ketones and aldehydes present in herbs are mainly associated with antibacterial actions.

Table.1 Antibacterial and antioxidant activity of Cinnamon and Ajwain extracts

\begin{tabular}{|c|c|c|}
\hline \multirow[t]{2}{*}{ Microorganisms } & \multicolumn{2}{|c|}{ Zone of inhibition (mm) } \\
\hline & Cinnamon & Ajwain \\
\hline S. aureus & 12 & 10 \\
\hline S. typhi & 7 & 7 \\
\hline P. aeruginosa & 16 & 15 \\
\hline P. vulgaris & 9 & 8 \\
\hline E. coli & 10 & 11 \\
\hline DPPH activity (\%) & 77.05 & 68.26 \\
\hline
\end{tabular}


The radical scavenging activity (DPPH) of methanolic extract of Cinnamon and Ajwain was found to be 77.05 and $68.26 \%$, respectively (Table 1). Cinnamon showed more antioxidant activity as compared to Ajwain. In accordance with current findings, Asimi et al (2013) observed \% inhibition (scavenging activity) of cinnamon to be 86.40 at $25 \mathrm{mg} / \mathrm{ml}$. Higher free radical scavenging activity of cinnamon (IC50 $13.1 \mu \mathrm{g} / \mathrm{ml}$ ) was reported due to presence of higher amount of phenolic compounds (El-Baroty et al 2010). Cinnamaldehyde and other flavonoids isolated from cinnamon possessed freeradical-scavenging activities and antioxidant properties (Okawa et al., 2001). In another study it was found that that cinnamon oil potentially exhibits superoxide-dismutase like activity as revealed by the inhibition of the inhibiting capacity of pyrogallol autoxidation (Kim et al., 1995). Significant radical scavenging activity was evident at all the tested concentrations of cinnamon bark and the EC50 value was found to be $4.21 \mu \mathrm{g} / \mathrm{ml}$ which was inversely proportional to the antioxidant capacity (Matthew and Abraham, 2006).

The results of antioxidant activity of Ajwain falls in agreement with that of Chattterjee and coworkers (2012) who revealed that at $240 \mu \mathrm{g} / \mathrm{ml}$ concentration of methonolic ajwain seed extract, the DPPH free radical scavenging activity was observed to be 83.42\%. Saxena et al (2012) also found radical scavenging activity of Ajwain seed extract to be $68.07 \%$. Ethanol extract of ajwain oil quenched $73.41 \%$ of DPPH radicals (Mazahir et al., 2015). Ajwain comprised carotenoids ( $\beta$-carotene and lutein), flavonoids and phenolic compounds (thymol) which provides powerful antioxidant protection. Due to presence of phytoantimutagens, there is inhibition of free radicals formation.
Concluding these results we can say that Ajwain and Cinnamon both exhibited considerable antibacterial and antioxidant activity which can be further explored to use them as an alternative to antibiotic growth promoters in animal feed for getting better production.

\section{Acknowledgement}

Authors are thankful to College of Veterinary and Animal Science, Bikaner for providing all the facilities and fund to pursue this research work.

\section{References}

Asimi, O. A., Sahu, N. P., and Pal, A. K. 2013.Antioxidant activity and antimicrobial property of some Indian spices. International Journal of Scientific and Research Publications, 3(3): 1-8.

Athanasiadou, S., J. Githiori and Kyriazakis, I. 2007. Medicinal plants for helminthes parasite control: facts and fiction. Animal. 1(9):1392-1400.

Chatterjee, S., Goswami, N., and Bhatnagar, P. 2012. Estimation of phenolic components and in vitro antioxidant activity of fennel (Foeniculum vulgare) and ajwain (Trachyspermum ammi) seeds. AdvBiores, 6(2): 109-18.

El-Baroty, G. S., Abd El-Baky, H. H., Farag, R. S., and Saleh, M. A. 2010. Characterization of antioxidant and antimicrobial compounds of cinnamon and ginger essential oils. African journal of biochemistry research, 4(6): 167-174.

Fulton, R. M., Nersessian, B. N., and Reed, W. M. 2002.Prevention of Salmonella enteritidis infection in commercial ducklings by oral chicken egg-derived antibody alone or in combination with probiotics. Poultry science, 81(1): 34- 
40.

Goni, P., Lopez, P., Sanchez, C., Gomez-Lus, R., Becerril, R., and Nerin, C. 2009.Antimicrobial activity in the vapour phase of a combination of cinnamon and clove essential oils.Food chemistry, 116(4): 982-989.

Hameed, I. H., Altameme, H. J., and Mohammed, G. J. 2016.Evaluation of antifungal and antibacterial activity and analysis of bioactive phytochemical compounds of Cinnamomum zeylanicum (Cinnamon bark) using gas chromatography-mass spectrometry. Oriental Journal of Chemistry, 32(4): 1769.

Khajeh, M., Yamini, Y., Sefidkon, F., and Bahramifar, N. 2004. Comparison of essential oil composition of Carum copticum obtained by supercritical carbon dioxide extraction and hydrodistillation methods. Food Chemistry, 86: 587-591

Kim, S. J., Han, D., Moon, K. D., and Rhee, J. S. 1995.Measurement of superoxide dismutase-like activity of natural antioxidants. Bioscience, biotechnology, and biochemistry, 59(5): 822-826.

Mathew, S., and Abraham, T.E. 2006.In vitro antioxidant activity and scavenging effects of Cinnamomum verum leaf extract assayed by different methodologies. Food Chem. Toxicol. 44: 198-206.

Mazahir, R., Anshul, K.S., Tatheer, F., and Shaista, 2015. A Comparative study of antioxidant activity of polyphenols isolated from frozen and fresh leaves of Trachyspermum ammi (ajwain). Journal of Pharmacognosy and Phytochemistry,
6:122-124.

Murray, P. R., Baron, E. J., Pfaller, M. A., Tenover, F. C., and Yolken, H. R. 1995.Manual of clinical microbiology, Washington DC: 15-18.

Nazzaro, F., Fratianni, F., de Martino, L., Coppola, L., and de Feo, V. 2013.Effect of essentials oils on pathogenic bacteria. Pharmaceutic. 6:1451-1474.

Okawa, M., Kinjo, J., Nohara, T., and Ono, M. 2001. DPPH (1,1-diphenyl-2Picrylhydrazyl) radical scavenging activity of flavonoids obtained from some medicinal plants. Biological and Pharmaceutical Bulletin, vol. 24: no. 10, pp. 1202-1205.

Salma, S., Ramakrishnan, L., And Vinothini, J. 2018.Screening of antibacterial activity of five different spices (ajwain, coriander, cumin, fennel, and fenugreek) against pathogenic bacterial strains. Screening, 11(2).

Sanchez-Moreno, C., Larrauri, J.A., and Saura-Calixto, F. 1998.A procedure to measure the antiradical efficiency of polyphenols. Journal of Science Food and Agriculture 76: 270-276.

Saxena, S. N., Agarwal, D., Saxena, R., and Rathore, S. S. 2012. Analysis of antioxidant properties of ajwain (Trachyspermum ammi L) seed extract.Int J Seed Spices, 2(1): 550-555.

Zarshenas, M.M., Moein, M., Samani, S.M., and Petramfar, P. 2013. An overview on ajwain (Trachyspermum ammi) pharmacological effects; modern and traditional. Journal of Natural Remedies, 14: 98-105.

\section{How to cite this article:}

Neha Sharma and Tribhuwan Sharma. 2021. Evaluation of Antimicrobial and Antioxidant Properties of Phytogenic Feed Additives. Int.J.Curr.Microbiol.App.Sci. 10(01): 2251-2255. doi: https://doi.org/10.20546/ijcmas.2021.1001.259 
Int.J.Curr.Microbiol.App.Sci (2021) 10(01): 2251-2255 